\title{
Epistemic Optimism, Speculation, and the Historical Sciences
}

\begin{abstract}
Adrian Currie*
I summarize the central ideas and arguments of Rock, Bone, and Ruin: An Optimist's Guide to the Historical Sciences, before responding to criticisms from Leonard Finkelman, Joyce Havstad, Derek Turner, and Alison Wylie. These cover whether, and to what extent, we can establish optimism about the historical sciences, the distinction between 'trace-based' and 'non-trace' evidence, the distinction between experiments and models, and the purpose and limits of speculation in scientific reasoning.
\end{abstract}

\author{
Keywords \\ speculation $\bullet$ epistemic situation $\bullet$ trace-based reasoning $\bullet$ historical science
}

Part of an author-meets-critics book symposium on Rock, Bone, and Ruin: An Optimist's Guide to the Historical Sciences (2018, MIT Press) by Adrian Currie, with Alison Wylie, Leonard Finkelman, Joyce C. Havstad, and Derek Turner.

\section{Synopsis}

Here's something I'm willing to claim we know: Homo sapiens, in particular the Polynesian settlers who first arrived in Aotearoa (New Zealand) around the twelfth century, take the lion's share of causal blame for the extinction of a lineage of enormous flightless birds: the moa. Stretching to three metres at their tallest, moa were a distinctive and remarkable feature of Aotearoa's primeval forests, playing the main browser and grazer role in this unique bird-based ecosystem. Once humans turned up forests were burned, moa were stalked, and human-introduced arrivals such as kiore (the Polynesian rat) had dramatic ecological repercussions. Within a few centuries, the moa were gone (Allentoft 2014) 1

1. Of course things are never so simple: Allentoft et al. are responding to Gemmell, Schwartz, and Robertson's (2004) argument that in fact Moa were already in decline prior to human arrival.

*Philosophy, Byrne House, Exeter University, UK EX4 4PJ, A.Currie@exeter.ac.uk

Received 27 March 2019; Accepted 2 April 2019 doi:10.3998/ptpbio.16039257.0011.007 
I'm much less confident of whether Aotearoa's example is projectable across the Pleistocene. That epoch carries a distinct pattern of extinction. This was no mass extinction (far from it) but targeted mega-fauna: if you don't live in Africa, and you weigh over $30 \mathrm{~kg}$ (which the moa certainly did) then chances are you're extinct (Martin and Klein 1989). Gone are the mammoth of the Steppes, South America's megatherium (giant land sloths), the enormous camels of North America, and Australia's gigantic diprotodon. The overkill bypothesis says-roughly-that the fate of the mammoth, megatherium, and diprotodon were like that of the Moa. That is: we did it (Ward 1998).

Let's distinguish two questions we might ask of the overkill hypothesis. First, What explains the epistemic security of the overkill hypothesis locally for Aotearoa, and the apparent epistemic insecurity of the hypothesis generally? Second, Should we be optimistic or pessimistic about the overkill hypothesis? The former question is a familiar one in the philosophy of science, roughly asking whether we should believe the hypotheses are true. The latter is less familiar, and although Rock, Bone, and Ruin has something to say about both, it is generally focused on questions of optimism.

Although I don't want to commit to the truth of the more general overkill hypothesis-I actually think it is likely false-I suspect we should nonetheless be optimistic about it. This means I think that historical scientists have the resources to come to know a lot about the Pleistocene's patterns of extinction by chasing that hypothesis. Rock, Bone, and Ruin, then, is structured using two broad positions: 'optimism' and 'pessimism'. Roughly speaking, an optimist believes that the strategies scientists adopt in light of their epistemic situations are productive strategies; that is, it is reasonable to expect epistemic dividends and expect them into the future. A pessimist denies this. Neither optimism nor pessimism are necessarily monolithic positions: one might be optimistic about some strategy in one context, pessimistic about it in another, and so on. My reason for adopting this framing is two-fold. First, it allows us to omit realism and anti-realism (which I think has stifled us philosophers of science), while still discussing scientific success and failure in a normative, epistemic key. Second, whether we are optimists or pessimists about an investigation matters: pessimists often recommend conservative methodological and epistemological approaches (which I think stymy science), and attitudes about pessimism and optimism likely matter for whether we think some scientific investigation is worth doing.

What perspective should we take when tackling questions like those posed above? I think we should consider what I've called epistemic situations (see also Leonelli 2016). An epistemic situation includes factors about the system at hand, and about the affordances (the knowledge, resources, techniques, etc.) of the scientists attempting to understand the system. This means that establishing optimism or pessimism is a fairly local business: by examining scientific practice we identify the strategies scientists adopt in light of their situations, and consider how those strategies are successful (or otherwise). One upshot of this is that I don't see establishing optimism or pessimism more generally as a matter of enumerative induction, of counting successes and failures. Instead, it involves establishing a situation-strategy match, and then examining it in relevantly similar or differing contexts. To figure out what is different about establishing the overkill hypothesis applied narrowly to Aotearoa's case, and the overkill hypothesis applied to the megafauna extinction more generally, we should ask after the epistemic situations faced. For instance, consider the relative logical strengths of the hypotheses at issue: confirming the general hypothesis would in turn confirm the particular, but not vice-versa. But that's only the beginning.

The extinctions in Aotearoa were upsettingly recent: Moa became extinct around 600 years ago. Compare this to, say, Australia or North America, where the megafaunal extinctions occurred tens of thousands of years in the past and time's decaying processes have had much more time to work. Moreover, the conditions of preservation between, say, Aotearoa and Australia are 
different, and often in ways which make establishing timing for the latter tricky. It is relatively easy to find evidence of Maori arrival, their effects on ecosystems, and of the moa's extinction. It is much more difficult to establish when $H$. sapiens arrived in Australia (estimates range from forty-thousand to tens of thousands of years earlier), and to establish their ecological effects. Further, Aotearoa was isolated in a way that, for instance, North America was not. Whereas in the former's case any non-endemic invasions (such as kiore) must be chalked up to human arrival, in North America H. sapiens were part of a more general invasion including, for instance, wolves. This makes it extremely difficult to isolate and determine $H$. sapiens's causal impact. Moreover, the Pleistocene was a time of dramatic climate change, and palaeontologists increasingly establish links between biotic turnover and climate disruptions. Finally—and I'll return to this briefly later-archaeologists have learnt to be suspicious of such simple, neat narratives: there being a single, human-driven cause of the extinctions is too neat to be plausible (Currie 2019).

The notions of epistemic situation and optimism/pessimism allow me to highlight something about the book. I'm not attempting anything like a delineation between historical and non-historical science-I'm not interested in defining or carving out a distinct kind of scientific practice which includes historical but excludes non-historical science. I'm not claiming that historical science is uniquely anything. I'm not inclined to find such distinctions particularly enlightening: the differences between practices and strategies adopted within research concerned with the past, and within the 'non-historical' sciences, are greater than between those two clusters, however we carve them. Instead, by appealing to epistemic situations, my hunch is that I can capture similarities both between and within various scientific strategies. Whether general clusters emerge- and what delineates those clusters - is, in my view, best approached from the bottom up. We begin with case-studies, systematize the strategies they adopt in response to the epistemic situation they find themselves in, and then look for further case-studies which appear to occupy similar epistemic situations. As things go along, our understanding of the case studies and our systematizations become further nuanced. That's my hope anyway.

How, then, do we establish optimism? To do so, we need to understand the epistemic situation some historical scientists face, and the majority of Rock, Bone, and Ruin attempts just that. The first half (chapters three through five) are about traces: the downstream remains of past events such as the fossils of extinct moa, various cultural remains indicating Maori arrival on Aotearoa, and so forth. In doing so, I develop an argument for pessimism that I try to debunk. The argument for pessimism claims that, first, historical inferences are always and only tracebased inferences; second, we should expect the traces which trace-based inferences rely upon to typically provide insufficient support; third, we should therefore expect historical inferences to typically have insufficient support. Let's take the premises in turn.

The first premise is a claim about the source of historical knowledge, namely that historical inferences are restricted to 'trace-based' inferences. But, I argue, this is a mistake. For one thing, historical inferences are not simply made between the present and the past, but between different events in the past. We don't simply link moa bones to once-living moa, and the remains of kumara, flax baskets, and kiore to the arrival of the Maori. We also link the Maori to the moa. I argue that these links-narrative connections, if you want-share epistemic structure with inferences between the present and the past. That is, I argue for a deflationary view about coherence that nonetheless vindicates the use of narratives in historical reconstruction (see also Currie 2016; Currie and Sterelny 2017). Because such inferences go beyond traces, they are a counterexample to the first premise. A further argument appeals to what we might call 'indirect' evidence: analogies and simulations. Analysing other extinction events might provide clues about how the Pleistocene extinctions occurred, and under the right conditions provide evidential support. With the right grounding, theoretical tools such as simulations can also play properly-speaking 
evidential roles, supporting and undermining some hypotheses in favour of others. Further, simulations allow us to actively generate new evidence: they sometimes enable historical scientists to be masters of their evidential destinies. Where the majority of philosophical attention has focused on trace-based evidence about the past, ${ }^{2}$ an examination of what historical scientists do when that avenue is limited reveals a range of non-trace sources of historical knowledge.

The second premise claims that we shouldn't expect trace evidence to improve over time: it is a kind of bet about the future availability of evidence. You might be tempted to refuse to bet, as Patrick Forber (2009) urges. I think there's something to this line of thought, but I also think it misses something critical. As Derek Turner (2016) has pointed out, such bets are the bread-and-butter of much scientific decision making:

Historical scientists and the institutions that fund their work have to make decisions about which questions are worth pursuing and which are best left for another day, or bypassed completely. Such decisions are an important part of scientific practice, and they surely involve complicated pragmatic cost/benefit calculations. (65)

So, if we must bet, how should we? Against a pessimistic outlook, I make two arguments: one, betting on pessimism buys into a bias; two, pessimism bets against the creativity and ingenuity of scientists. The former argument turns on my (and others') emphasis on scaffolding in science (Walsh forthcoming; Chapman and Wylie 2016; Wimsatt 2014). I've argued that evidential relevance is opaque and dynamic. What evidence might turn out to be relevant will change as the investigation proceeds. 3 This means that attempts to determine the evidential fate of a hypothesis prior to the investigation will likely be biased. And especially so, considering scientific ingenuity, particularly in terms of the co-option, adaptation and development of new techniques and technologies to the needs of historical scientists. Historical scientists often focus on honing and developing such techniques, and adapting them to their local contexts-they're methodological omnivores. No doubt other scientists do this as well, but nonetheless I'm struck by how often methodological innovation is the aim of research in paleontology and archaeology.

These arguments undermine a position regarding pessimism, but what has this to do with a positive position regarding optimism? The claims I make concerning the epistemic resources available to historical scientists - their use of narrative coherence, analogies, simulations, and the opportunistic strategies they adopt - are successfully used in unlucky epistemic situations. I define these as situations where we should expect trace-evidence, the remnants of the past, to be particularly crappy, the past's signal particularly degraded and distorted. If I can defend against pessimism in those circumstances, then assuming those strategies are open in other context, this motivates a more general optimism about our capacity to uncover the past. If we can do so well when things are tough, presumably we should also do well when conditions are more epistemically amenable.

Having said this, I suspect that focusing so much on whether I establish optimism is to undersell the book. In the reviews of Rock, Bone, and Ruin there are, in a sense, two interpretations: on the one hand, the book is an argument for optimism about the historical sciences; on the other hand, discussion of optimism and pessimism is a framing device to motivate examination of the methodological and epistemic nature of historical reconstruction (or, more generally, how science works in 'unlucky situations'). Along these lines, I think what really matters about optimism and pessimism is how they focus our analyses on understanding how, in practice,

2. With some notable exceptions such as Jeffares 2008 and Turner 2013.

3. I think adaptions of Toulmin's argument-schema (see Chapman and Wylie 2016; Bonnin forthcoming) make this point clearly: often, it is only in reaction to possible rebuttals for evidential claims that further evidence becomes relevant.

๑ OPEN ACCESS - PTPBIO.ORG 
historical scientists generate knowledge. Fundamentally, I hope Rock, Bone, and Ruin plays a role in retooling how philosophers approach and think about scientific success and method into more local, practice-oriented ways. And further in reorienting how we think about scientific success - as opposed to the narrow focus on truth or empirical adequacy which is the legacy of the realist/anti-realist framing-we can consider the epistemic products of science in a much richer way ${ }^{\text {] }}$

I draw three lessons about the nature of science (at least in unlucky circumstances) and two related lessons for the philosophy of science. First, messiness: scientific expertise, evidence, and disciplinary structures are disunified - there is no overweening theory or single hierarchical structure to the justification of scientific inferences about the deep past. This enables multiple perspectives to simultaneously build knowledge. In disunity there is power (Wylie 1999). Second, speculation: speculative hypotheses play a crucial role in driving progressive science by providing scaffolds from which new evidence may be discovered. Third, methodological omnivory: part of the strategy of historical science is to opportunistically co-opt, adapt and construct local in-house inference-tools which maximize how much evidence can be generated. For the philosophy of science I emphasize first localness: philosophical explanations of scientific reasoning need to attend to the local details. Highly abstract, formal methods often lack explanatory power. And second, practice: philosophical understanding of scientific success (and failure) cannot be achieved by attending to the products of scientific work (their hypotheses and evidence) alone, but only by also attending to the social and epistemic processes involved in generating those products.

My hope is that such reframing and the lessons that come with it stand on their own, in part irrespective of whether we agree on pessimism or optimism. The notion of speculation I articulate in the book argues that the value of a hypothesis does not turn on the likelihood of its truth, but on what routes to new knowledge it opens up. My hope for Rock, Bone, and Ruin is that it is an instance of this kind productive speculation: so for the historical sciences, so also for philosophy itself.

\section{Response to Critics}

Philosophy — like most human activity — is fundamentally social. The lone philosopher, carving conceptual truths from the cliff-face of the interface of mind and world, wielding only their nuance, intuition, and rationality, is a myth. Or at least it never appealed much to me. So it's a great privilege to have incisive and engaged critiques of Rock, Bone, and Ruin, and I hope my response does justice to them. Both Joyce Havstad and Leonard Finkelman have challenged my optimism, in different but complementary ways, Derek Turner draws attention to the downsides and dangers of speculation, while Alison Wylie both puts pressure on how I conceptualize tracebased evidence and reflects on methodological pluralism within philosophy. I'm going to tackle Havstad and Finkelman together, before turning to speculation and Turner's critique. But I'll bookend everything with Wylie's contribution.

Alison Wylie's work emphasizes the power of the material archaeological record: its obstinate capacity to challenge preconceptions about the past and underwrite well-supported often surprising hypotheses. This focus on traces—on “Thinking from Things" (Wylie 2002)—rather naturally leads Wylie to identify her views with tracecentrism. It is worth noting that, by my account at least, Wylie is no tracecentrist. Tracecentrists don't simply think that our epistemic

4. Indeed, as Turner (forthcoming) argues, we can expand these goods still further to include the aesthetic as well.

๑ OPEN ACCESS - PTPBIO.ORG 
access to the past is in some sense importantly dependent upon traces; they also adopt a narrow construal of what traces are or what trace-based reasoning involves, and thus what sources of evidence we might find in the record. And Wylie's accounts of archaeological evidence are anything but narrow:

[archaeological evidence] emanates from disparate elements of the archaeological record, draws on background knowledge that originates in diverse source fields, and bears on an array of conditions and events that constitute the complicated lives of the material things that make up the archaeological record. (Wylie 2011, 386-387)

Wylie emphasizes what I call evidential 'confluence' (Currie 2018, 161-165): in typical historical reconstruction multiple and varied strands of evidence are woven together in complex ways, necessitating holist approaches to justification. Wylie thus handily shows that a focus on traces needn't go hand-in-hand with impoverished conceptions of historical evidence. So why have I insisted on distinguishing between 'trace' and 'non-trace' evidence in such a stark way? Answering is another opportunity to return to Aotearoa's distinctive fauna.

Kiwi, the moa's comparatively diminutive relatives, are odd birds. Besides the rather obvious lack of flight, they have soft, almost downy feathers, their sense of smell is extremely acute, and they are nocturnal grub-eaters; at home in burrows dug into the wet forest floor. In many ways, they are birds adapted to a typically mammalian way of life. Badgers, for instance, share many of the same traits. Let's distinguish between two kinds of evidence relevant for explaining why kiwis are the way they are. First, kiwis are birds - they hail from a particular ancestral lineageand this explains their wings, their feathers, their egg-laying, and so forth. Such explanations are enabled by the historical continuity between the kiwi and related birds. Aves have a common history, linked together by patterns of reproduction and ancestry. This relative stability across generations enables inferences from bird taxa to bird taxa. Second, as we've seen, kiwis occupy a particular niche, adapted to a life of nocturnal, burrow-dwelling foraging. Other critters look similarly adapted. In light of this we might, for instance, use badgers to help inform our understanding of just how the kiwi's traits are adapted to their lifestyle. The kiwi's emphasis on smell rather than sight, for instance, has been considered in just this way:

reliance upon tactile and olfactory information over visual information is found in both Kiwi and in nocturnal mammals such as rodents. This suggests the independent evolution in Kiwi and in these mammals of similar sensory performance that is tuned to a common set of perceptual challenges presented by the forest floor environment at night that cannot be met by vision. (Martin et al. 2007, 198)

When appealing to biological convergence in this fashion, biologists try to ensure that the traits in question evolved independently as opposed to being inherited from a common ancestor. Otherwise, the traits could evidence ancestral relationships rather than environmental adaptation. These two kinds of evidence, then - ancestral and convergent-are used to support explanations of biological form and function in different ways (Currie 2012). My distinction between trace and non-trace evidence basically tracks the difference between ancestral and convergent evidence.

By 'trace' evidence I refer to cases akin to the ancestral relationships between kiwis and other birds. That is, relationships composed of causal chains which support inferences: these I term 'downstream' relationships (194-195). As we've seen, one example of 'non-trace' evidence are biological convergences. Here, independent instances of a general type can be used to evidence models of those types. The same distinction is found in the archaeological notion of 'direct' and 'indirect' ethnographic analogies (Currie 2016a; Wylie 1985). The former infers along lines 
of cultural continuity from an ethnographic report of a recent culture to their ancestors; the latter uses unconnected cultures to inform reconstructions. The distinction between trace and non-trace evidence, then, concerns epistemic function. When an inference is made on the basis of causal ancestry, it is a trace-based inference. When an inference is made on the basis of comparisons between our target and analogues who have been independently shaped by similar processes, it is not. Sometimes objects are used as traces, sometimes as analogues. And differing inductive logics apply depending on the use. In explaining the kiwi's evolution, I'll surely bring to bear both ancestry and convergence. However, that historical scientists integrate both doesn't undermine the distinction's epistemic and conceptual grounding. But like any distinction, its usefulness will depend on context.

One reason in favour of a strict trace/non-trace distinction is dialectic. The distinction between trace and non-trace evidence can serve to highlight how impoverished some notions of historical evidence are: they demonstrate just how different tracecentrist accounts are from Wylie's rich, confluence-based discussions of historical evidence. Another advantage is making explicit and analysing the myriad evidence and strategies historical scientists have at their disposal. Just as splitting trace from non-trace evidence risks missing the integration of evidence, lumping them together risks missing the differing kinds of reasoning that come together in evidential confluence. A similar point applies to Wylie's suggestion that I draw an ever-closer association between models and experiments.

Although I argue that simulations are a means of generating historical evidence and thus perform experiment-like roles, I resist the idea that there is no useful distinction between experiments and models to be had. Arnon Levy and I draw the two apart by considering how experiments and simulations are validated. In particular, how we reassure ourselves that the object we examine, and the results we produce, are revelatory of our ultimate target (Currie and Levy forthcoming). In an experiment, we use various techniques to reassure ourselves that our specimen is a relevantly typical instance of the class we're interested in, and that the various ways in which it has been altered to be amenable to experimentation won't lead to artefacts: results that are due to the setup of the experiment or the subject's departures from typicality. The subjects of experiments, then, are specimens, drawn from a population of the things we're interested in understanding. Modelling involves theoretical representations of targets, thus asking after their typicality vis-à-vis the target would be odd indeed. Models aren't supposed to be typical instances of the thing they model, but rather appropriately idealized surrogates. This needn't obscure the similarities between experiments and models, nor deny that many instances of scientific testing and measurement involve modelling and experimentation together. And it also needn't clash with our taking seriously the materiality of the surrogate, nor deny the possibility of mixed cases. However, thinking that experiments and models are instances of the same kind of epistemic activity is to confuse the empirical with the theoretical, observations with ideas, and being representative with being a representation. Theory and observation are no doubt inextricably epistemically linked, but that doesn't make them conceptually apiece. To reiterate, though, whether the distinction matters - whether it is crucial to the discussion-will turn on context. There may be times when lumping together experiments and simulations won't harm an analysis: just don't insist that there is no distinction to be had.

As we've seen, the central arguments of Rock, Bone, and Ruin concern optimism and pessimism. Optimists and pessimists tend to adopt different strategies in their research - pessimism is often connected with conservative epistemologies for instance. Relatedly, optimism or pessimism makes a difference to which research we think pursuable. Joyce Havstad and Leonard Finkelman undermine optimism from two quite different angles. I think their objections can be met. 
Part of Havstad's worry is the suspicion that I load the die by describing the Ripple Model of Evidence as I do. The metaphor I employ asks the reader to imagine dropping a pebble into a pond and taking photographs of the subsequent ripples. Havstad points out that this latter aspect - the photographs - makes pebble-dropping-events look much more informationpreserving than they are in reality. I suspect it is a red herring: I can decouple model from metaphor. By the ripple-model, three factors influence an event's retrievability on the basis of traces. First, dispersal, that is, the number and diversity of downstream traces; second, faintness, the distortion of downstream traces; third, gappiness, how complete downstream trace-sets are. I suggested that each of these features ceteris paribus increase over time. We can think of how much knowledge trace evidence generates (in the narrow trace-centrist's sense) in terms of the epistemic push of dispersal and the epistemic pull of faintness and gappiness. Havstad suggests that real stone-dropping events (those without attentive photographers) are very low in dispersal, high in gappiness, and high in faintness. In other words, they are 'unlucky circumstances'. That looks right. However, with the account unwoven from the metaphor, it doesn't strike me that the dice are loaded - the point of the model is to bring out unlucky circumstances, not to make a claim about the ease or otherwise of the circumstances they capture. As we'll see, Havstad's objection is more pressing than this, but to get to it, I want to first discuss Leonard Finkelman's argument.

Finkelman considers how dependencies between 'biological hierarchies' underwrite inferences, enabling epistemic navigation between differing information about the past. We don't need to see a moa with preserved feathers to posit a feathered body; its skeleton's clear signs of birdhood are sufficient. Although I've some reservations about 'hierarchy' talk (Potochnik and McGill 2012), I take it that Finkelman's point is that an organism's having some specific properties makes it more likely for it to possesses other properties as well-and when those links are sufficiently tight and well-established, this allows us to push our knowledge into the deep past, even when based on apparently meagre traces. These inferences between 'hierarchies', I take it, are biological versions of chapter 6's 'coherence-testing'. There (and in Currie 2016b) I argue that one way in which the Ripple Model fails to capture all of our epistemic resources is that it doesn't attend to the connections between our hypotheses in the past. Even if trace sets are gappy, faint and of high dispersal we can sometimes, as Finkelman describes, still make firm inferences so long as the features we do know about highly constrain or determine other features.

Finkelman describes how paleontologists make differing bets depending on whether they think there are sufficiently constraining features or not. Due to our not knowing the relationship between some of Tiktaliik's morphology and its forelimbs, Tiktaliik's forelimbs were underdetermined in a way that moa's feathers are not. According to Finkelman, pessimism is appropriate in those cases where the connections between something's properties are insufficiently constraining. Further, discovering such connections relies on finding the right traces. If we hadn't found more traces of Tiktaliik or her relatives we would have had no hope of reconstructing its forelimbs. This latter point leads Finkelman to argue that my optimism about historical reconstruction in fact relies on finding more fossils. For all my attempts to show that we can transcend traces, my optimism about paleontology turns on a bet that bountiful new fossils will be found.

I think Finkelman's assumption that finding new fossils is necessary to empirically understand biological hierarchies, that paleontological 'Rosetta Stones' are required to unlock these mysteries, is mistaken. His view reminds me of Turner's (2007) discussion of fossilized dinosaur hearts:

Although they can develop new technologies for identifying and studying potential smoking guns ... historical scientists can never manufacture a smoking gun. If, in 
fact, every single dinosaur heart was destroyed by the fossilization process, there is nothing anyone can do about it. (58)

No doubt one way of resolving the tricky situations Finkelman highlights—solving the mystery of Dimetrodon sails, for instance-is via the lucky discovery of a beautifully-preserved soft-tissue sail: a Rosetta Stone. But I insist that is not the only way.

Finkelman follows Turner (2016) in contrasting bets against the methodologies of paleontologists and bets against new fossil discoveries. Like Turner, Finkelman thinks betting against the former is a bad idea-paleontology's methodologically omnivorous, ever-expanding tool-kit makes it very hard to predict what they'll be able to do in the future. In the latter case however it seems that Finkelman is more willing to bet against paleontologists. They might develop a whole range of fancy new analyses, but they're unlikely to find many Rosetta Stones. However, I think the methodology of historical scientists and the traces which are available to them are not independent. I've argued that there are two ways of finding new traces—via discovery and via refinement (Currie 2018, 95-96). The latter involves re-examining existing finds as new technologies and background knowledge come online. Finkelman's bet that we won't discover the function of Dimetrodon sails is not, then, only a bet that we won't find Rosetta Stones via discovery from fieldwork. It is also a bet that we won't find them through developing new technologies that reveal (in a sense) that a Rosetta Stone has been under our noses the whole time. The argument, then, fails: you don't get to claim that bets against discovering past facts turn on unlikely fossil finds alone; you also need to bet against refinement. Further, this assumes that surrogatebased testing - the use of biomechanical modeling for instance-couldn't manufacture evidence pertaining to the Dimetrodon's sail.

Does this mean we should bet in favour of scientists discovering the function of Dimetrodon sails? I'm not sure, to be honest-I'll discuss the specificity of bets below-but it does mean that Finkelman's argument that optimism about uncovering the past depends on optimism about finding future fossils, fails. With this in place, I can now turn back to Havstad's objection.

Havstad's argument has two parts. First, she identifies a weak point in Rock, Bone, and Ruin: I don't establish that there are not processes, events, and entities in the past that have been erasedleft no traces in the present. Second, she argues from this weak point that the best position is neither optimism nor pessimism, but instead agnosticism. As we don't know whether the past is populated with many information-erasing processes or not, we should withhold judgment.

Havstad's first point - that we are ignorant about information destruction or retentionbrings to mind Ben Jeffares's discussion of Elliott Sober's (1991) 'bowl' metaphor. Sober uses the case to introduce the information-destruction/retention distinction. He asks us to imagine a perfectly concave bowl. A round ball dropped into the bowl will come to rest at the bowl's centre regardless of where it was released. In such cases, because the ball's resting place is not sensitive to its starting position, the ball being in the centre of the bowl provides no information about the ball's initial position at the point of release. Information is not preserved (see also my discussion of Calgary's C-train, 68). Jeffares's discussion is worth quoting in some detail:

in a messy world, there may well be additional factors that allow us to narrow down the starting position of the ball, and determine its trajectory. An actual bowl may force the experimenter to release the ball from a limited portion of the rim, due to lack of reach, or other factors related to the actual circumstances. A bowl that has only been used once may have a fine layer of dust on it. In such a situation, a ball would remove a fine trail of dust from the surface, revealing an elegant and precise trajectory and starting point for the ball. Depending on the composition of the ball, one might dust for the "fingerprint" of the ball, as a slight layer of grease from 
human handling is deposited on the bowl's surface. I wouldn't bet on the trajectory of balls in bowls being unknowable, anymore than dinosaurs frankly. (Jeffares 2010, 140)

Jeffares's point is that Sober's example leans on our isolating the bowl from outside influenceonly in the artificial circumstances where we consider the relationship between bowl and ball alone does information destruction look plausible.

surely there are systems, such as the ball in the bowl suggested by Sober, which are such that they do not preserve evidence? This too, surprisingly, is an empirical question. The slip with this example is to argue from an isolated model system, rather than acknowledge that historical sciences work in that complex, messy world outlined above. Simple, closed systems really are difficult, but events in the world are messy, complex, and rarely closed. (Jeffares 2010, 139-140)

Jeffares links information preservation to messy, interdependent, open systems. Note that in such systems faintness will increase-the connections between traces and their past causes will often be indirect - but that is very different from information not being preserved at all, as in the isolated bowl's perfect convergence. Jeffares's connection between open systems and information preservation suggests we can respond to Havstad. If we should only expect complete information-destruction in isolated, closed systems, then her argument turns on whether we should expect such systems to exist (or to have existed). As Jeffares points out, such systems are extremely rare in nature. So the messiness of the world comes to our rescue: we should expect information-retention.

However, it may be that I have interpreted Havstad in far too abstract terms. Havstad's discussion of pebbles settling at the bottom of a pond is evocative: it really does seem unlikely that we could figure out the particular path each pebble took to its resting place. But this isn't a claim about what information has been retained, it is a claim about our knowledge of pebbleand-pond dynamics; we simply lack the know-how to perform the reconstruction. This returns us to where we left off with Finkelman: on this interpretation, Havstad's argument turns on a bet against methodological omnivory. I suspect that if, for whatever reason, historical scientists decided that understanding the lives of pond pebbles were a critically important task, the science of pebble-and-pond dynamics would progress apace. Either, then, Havstad's agnosticism requires we argue that most systems are closed-pretty unlikely —or it requires that we bet against the ingenuity of historical scientists. This doesn't require thinking that a flourishing science of pebble-pond dynamics lies in our future. I suspect this is contingent on historical scientists caring enough to ask such questions, as opposed to whether in such cases information has, in principle, been retained. Nor does thinking this require me to think that all facts are recoverable (see my discussion of optimism ${ }_{\mathrm{G}}, 282-283$ ).

Although I don't think Finkelman's nor Havstad's arguments should turn us from optimism, they do press on what I think is a real tension in how Rock, Bone, and Ruin treats optimism and the discovery of past facts. It seems that I can be quite optimistic about historical scientists in rather imprecise ways - that is, that they'll uncover a lot of fascinating and important information concerning the past-but putting one's finger on exactly what information they will discover (and how!) is particularly difficult. This is especially so given my emphasis on indirect epistemic goods, on the unintended upshots of science. And especially so given the emphasis I put on scaffolding in investigation and how this makes the future of research opaque. It may be, then, that I am licensed to think that many epistemic dividends will be the result of the opportunistic, methodologically omnivorous approaches that some historical scientists adopt, 
while not at all being licensed to identify just which questions will be answered. There is then a tension between 'precision-optimism' about uncovering particular facts concerning the past (at least in unlucky circumstances), and the indirect, productive, and scaffolded nature of historical reconstruction. I'm quite happy to embrace 'imprecise-optimism' in unlucky circumstances: there is still plenty of room in luckier cases to be confident of our capacity to discover particular facts, and it is worth bearing in mind that optimism is about far more than simply whether we will uncover facts about the past-my pluralism about epistemic goods extends to features like understanding, possibility exploration, and so forth. In a pluralistic mood, being unable to zoom in on what, exactly, we'll discover about the past seems to me positively invigorating.

It is also worth briefly reflecting on Havstad's position: Is agnosticism actually an available option? Certainly, if we construe optimism and pessimism as positions that philosophers might adopt regarding the epistemic prowess and success of historical science, then we might decide the evidence is insufficient and withhold judgement. But both historical scientists themselves and those who fund them have to make decisions about pursuability (Turner 2016), and in part pursuit turns on judgements about pessimism or optimism: Which research paths are more likely to provide epistemic dividends? In such contexts, it seems to me, we are forced to bet. Having said this, it would be interesting to consider what an agnostic strategy to pursuit would look like. Perhaps under conditions of epistemic indifference we should spread our bets, maybe incorporating chance factors (Avin forthcoming). In chapter 12, I associated these more exploratory strategies with optimism, but perhaps they could equally well be the domain of the agnostic. Agnostics might be fans of exploratory speculation too.

Speaking of speculation, Derek Turner objects that while I make the positive case for speculation, I ignore its dark side. The objection is well-made, and presents an opportunity to reflect on the consequences of Taking Speculation Seriously (the caps, of course, indicating the gravity of the suggestion!). To begin, Turner rightly expresses some bafflement regarding the term 'empirically-grounded speculation'. The point of the phrase 'empirical grounding' was to emphasize how the speculation came from deep engagement with empirical details (rather than simply making things up) and to highlight how the aim of the speculation is to open new routes to empirical knowledge. Perhaps a better term—which I'll adopt here-is 'productive' speculation. Kim Sterelny and I have distinguished between productive and idle speculation, the latter being speculative hypotheses which fit the available evidence but do not drive research further ${ }^{5}$ In light of Turner's point (and a similar argument Derek Skillings made in his review, 2018) perhaps we should add a new category: egregious speculation. This is speculation which does not merely fail to drive investigation forwards, but undermines it.

Turner's discussion highlights two kinds of egregious speculation. The first involves reinforcing existing biases. Here, the speculation reflects pre-existing ideas which themselves lack proper evidential support. Resistance to the general overkill hypothesis is in part driven by suspicion that its plausibility is due to being an all-too-simple, all-too-easy story which reinforces ideas of $H$. sapiens as extinction-driving machines which, while being true of our current state of play, might not have held in the past. Feminist analyses of science provide a veritable treasure trove of examples of reinforcing egregious speculation. The second kind involves misinformation. Part of Turner's worry about the combative dinosaur exhibition is that it might lead the public to false ideas about what the past was like, or how much we know about it. One might think that in pedagogical contexts we are obligated to present the most up-to-date science insofar as we

5. Hernan Bobadilla has suggested that, given my pluralism about epistemic goods, it is unlikely that idle speculation really occurs. I suspect he may be right, but there could well be circumstances where some speculation approaches it. 
can. At least one of the things that make creationist museums insulting is dressing up fictions in the garb of science-communication.

Notice that any particular speculative hypothesis might include both egregious and productive elements. It might reflect long-held ideas in a non-reflexive way (so be egregiously reinforcing) yet still open up new empirical research; it might be an extremely fruitful new hypothesis, yet still be misleadingly presented as an established truth in media reports. This means that making the most of speculation's power involves mitigating the egregious aspects. For instance, Kirsten Walsh and I have argued that under some (highly limited) pedagogical conditions facts may be legitimately distorted if those distortions are likely to increase the uptake of the knowledge we're interested in imparting. However, we've also suggested that if one is going to do this-employ myths in order to up pedagogical uptake- "one could teach the myth as a myth" (Walsh and Currie 2015, 423 italics in original). Along these lines, presentation of speculative ideas in museums could be an opportunity to encourage the public to engage critically with the nature of scientific knowledge. For the highly speculative Smithsonian exhibit that Turner discusses, the museum could accompany the "recreation" of Tyrannosaurus rex's kill strategy with a video or an information board explaining the evidence underwriting the hypothesis, and perhaps encouraging participants to think about alternative hypotheses, or alternative ways of testing them. A simple example of this strategy is to use colour differentiation to distinguish between the parts of a skeleton for which we have specimens and those that are inferred. Such ways of presenting speculation could make for gripping spectacles while still engaging the public about both what we know about the past and the nature of scientific reasoning.

Now, let's consider egregious speculation involving reinforcement: speculation that only reflects our own prejudice. Any instance of scientific reasoning will be at some risk of this occurring, as there is no 'view from nowhere' (Douglas 2009), so the point must be that speculation is particularly prone to this. This is, presumably, because speculation's running-ahead-of-theevidence makes the evidence we have less constraining, and thus there is more opportunity for our biased prejudice to be in the driving seat of interpretation (Bell 2015). I'd be surprised if there were too many systematic things to say here, but it strikes me that this kind of bias would be subject to the same mitigating rules-of-thumb as always. A diversity of views is often cited as a way of combating bias (Longino 2002), as is turning away from incentive structures which encourage conservatism (Currie forthcoming). A more openly speculative science might need to rethink some publishing practices, how scientific papers are written, and how they are presented in media contexts: as opposed to treating papers as expressing truth (being a single block in a wall of facts, if you'd like) perhaps they should be conceived as part of ongoing conversations, and be valued for laying their ambiguities - where the evidence runs out - bare (as Joan Gero has suggested for archaeology, 2007). Or perhaps new 'exploratory' papers could be added to the types of papers that can be published. If so, this would require understanding what might make for a good exploratory paper. Finding space for speculation in science, then, doesn't simply involve providing the kinds of epistemic arguments Rock, Bone, and Ruin trades in; it also requires thinking about how to promote productive - while minimizing egregious - speculation within and without scientific communities. And this turn to the social structure of science brings me back to Alison Wylie's essay.

Wylie closes her discussion by turning methodological omnivory onto philosophy itself. That is, if we wish the philosophy of science to be an explicitly normative practice able to engage with, critique, and even fruitfully shape scientific activity, we philosophers must expand our tool-kit. This involves taking the anthropology, history, and sociology of science seriously, as much as it does actively engaging with (and even doing) scientific work ourselves. Many philosophers already do this, of course, and I also don't think this stance means we mustn't engage in abstract 
analyses of mysterious puzzles. (I've perhaps slightly more time for sterile scholastic debates than Wylie!) But it does mean we should think hard about how to make an increasingly synthetic philosophy of science possible. I think new directions which incorporate empirical methods into philosophy - adopting theoretical tools from evolutionary biology and economics, for instance, embracing the importance of non-epistemic values in science, and making increasing use of information from, and in collaboration with, other disciplines-is part of what makes doing the philosophy of science exciting right now. If such trends continue and spread, I'll happily report that my optimism applies not only to the historical sciences, but to the philosophy of science as well.

\section{Acknowledgments}

Many thanks to Joyce Havstad, Derek Turner, Leonard Finkelman and Alison Wylie for their wonderful commentaries, and to Derek Turner, Joyce Havstad and Thomas Bonnin for feedback on the synopsis. I'm grateful to the participants of the 2019 "Science and the Deep Past" workshop at the University of Tartu, who helped strategize and develop my responses. Some of these ideas were first presented at the 2018 Society for Philosophy of Science in Practice Conference, thanks to the participants and audience there. Some of the research for this paper was funded by the Templeton World Charity Foundation.

\section{Literature cited}

Allentoft, Morten Erik, Rasmus Heller, Charlotte L. Oskam, Eline D. Lorenzen, Marie L. Hale, M. Thomas P. Gilbert, Christopher Jacomb, et al. 2014. "Extinct New Zealand Megafauna Were Not in Decline Before Human Colonization." Proceedings of the National Academy of Sciences 111 (13): 4922-4927. doi:10.1073/pnas.1314972111.

Avin, Shahar. n.d. "Mavericks and Lotteries." Studies in History and Philosophy of Science Part A. doi:10. 1016/j.shpsa.2018.11.006.

Bell, Martin. 2014. "Experimental Archaeology at the Crossroads: A Contribution to Interpretation or Evidence of 'Xeroxing'?” In Material Evidence: Learning from Archaeological Practice, edited by Robert Chapman and Alison Wylie. New York: Routledge.

Bonnin, Thomas. n.d. "Evidential Reasoning in the Historical Sciences: Applying Toulmin Schemas to the Case of Archezoa." Biology and Philosophy. doi:10.1007/s10539-019-9677-z.

Chapman, R., and A. Wylie, eds. 2015. Material Evidence: Learning from Archaeological Practice. London: Routledge. doi:10.4324/9781315739274.

Cleland, Carol E. 2002. "Methodological and Epistemic Differences Between Historical Science and Experimental Science.” Philosophy of Science 69 (3): 447-451. doi:10.1086/342455.

Cleland, Carol E. 2011. "Prediction and Explanation in Historical Natural Science." The British Journal for the Philosophy of Science 62 (3): 551-582. doi:10.1093/bjps/axq024.

Currie, Adrian. 2012. "Convergence as Evidence." The British Journal for the Philosophy of Science 64 (4): 763-786. doi:10.1007/s10539-012-9319-1.

Currie, Adrian. 2016a. "Ethnographic Analogy, the Comparative Method, and Archaeological Special Pleading." Studies in History and Philosophy of Science Part A 55:84-94. doi:10.1016/j.shpsa.2015. 08.010 . 
Currie, Adrian. 2016b. "Hot-Blooded Gluttons: Dependency, Coherence, and Method in the Historical Sciences." The British Journal for the Philosophy of Science 68 (4): 929-952. doi:10.1093/bjps/ axw005.

Currie, Adrian. 2018. Rock, Bone, and Ruin: An Optimist's Guide to the Historical Sciences. Cambridge, MA: MIT Press.

Currie, Adrian. 2019. "Simplicity, One-Shot Hypotheses and Paleobiological Explanation." History and Philosophy of the Life Sciences 41 (1): 10. doi:10.1007/s40656-019-0247-0.

Currie, Adrian. n.d. "Existential Risk, Creativity and Well-Adapted Science." Studies in History and Philosophy of Science Part A. doi:10.1016/j.shpsa.2018.09.008.

Currie, Adrian, and Arnon Levy. n.d. "Why Experiments Matter." Inquiry: 1-25. doi:10.1080/002017 4x.2018.1533883.

Currie, Adrian, and Kim Sterelny. 2017. "In Defence of Story-Telling." Studies in History and Philosophy of Science Part A 62:14-21. doi:10.1016/j.shpsa.2017.03.003.

Douglas, Heather. 2009. Science, Policy, and the Value-Free Ideal. Pittsburgh PA: University of Pittsburgh Press.

Forber, Patrick. 2009. "Spandrels and a Pervasive Problem of Evidence." Biology and Philosophy 24 (2): 247. doi:10.1007/s10539-008-9144-8.

Gemmell, Neil J., Michael K. Schwartz, and Bruce C Robertson. 2004. "Moa Were Many." Proceedings of the Royal Society of London. Series B: Biological Sciences 271 (Supplement 6): S430-S432. doi:10.1098/rsbl.2004.0234.

Gero, Joan M. 2007. "Honoring Ambiguity/Problematizing Certitude.” Journal of Archaeological Method and Theory 14 (3): 311-327. doi:10.1007/s10816-007-9037-1.

Jeffares, Ben. 2008. “Testing Times: Regularities in the Historical Sciences.” Studies in History and Philosophy of Science Part C: Studies in history and philosophy of biological and biomedical sciences 39 (4): 469-475. doi:10.2307/4018995.

Jeffares, Ben. 2010. "Guessing the Future of the Past." Biology and Philosophy 25 (1): 125-142. doi:10. 1007/s10539-009-9155-0.

Leonelli, Sabina. 2016. Data-Centric Biology: A Philosophical Study. Chicago: University of Chicago Press.

Longino, Helen E. 2002. The Fate of Knowledge. Princeton University Press.

Martin, Graham R., Kerry-Jayne Wilson, J. Martin Wild, Stuart Parsons, M. Fabiana Kubke, and Jeremy Corfield. 2007. "Kiwi Forego Vision in the Guidance of Their Nocturnal Activities." PLoS One 2 (2): e198. doi:10.1371/journal.pone.0000198.

Martin, Paul S., and Richard G Klein. 1989. Quaternary Extinctions: A Prehistoric Revolution. University of Arizona Press.

Potochnik, Angela, and Brian McGill. 2012. “The Limitations of Hierarchical Organization.” Philosophy of Science 79 (1): 120-140. doi:10.1086/663237.

Skillings, Derek. 2018. "Review of Rock, Bone, and Ruin.” Notre Dame Philosophical Revierws. doi:10. 7551/mitpress/11421.003.0001.

Sober, Elliott. 1991. Reconstructing the Past: Parsimony, Evolution, and Inference. Cambridge, MA: MIT Press.

๑ OPEN ACCESS - PTPBIO.ORG 
Turner, D. n.d. Paleoaesthetics. Cambridge University Press. Forthcoming.

Turner, Derek. 2005. "Local Underdetermination in Historical Science." Philosophy of Science 72 (1): 209-230. doi:10.1086/426851.

Turner, Derek. 2007. Making Prehistory: Historical Science and the Scientific Realism Debate. Cambridge University Press.

Turner, Derek. 2013. "Historical Geology: Methodology and Metaphysics." Geological Society of America Special Papers 502 (2): 11-18. doi:10.1130/2013.2502(02).

Turner, Derek D. 2016. “A Second Look at the Colors of the Dinosaurs." Studies in History and Philosophy of Science Part A 55:60-68. doi:10.1016/j.shpsa.2015.08.012.

Walsh, Kirsten. n.d. "Newton's Scaffolding: The Instrumental Roles of His Optical Hypotheses." In Experiment, Speculation and Religion in Early Modern Philosophy, edited by A. Vanzo and P Anstey. Routledge.

Walsh, Kirsten, and Adrian Currie. 2015. "Caricatures, Myths, and White Lies." Metaphilosophy 46 (3): 414-435. doi:10.1111/meta.12139.

Wimsatt, William C. 2014. "Entrenchment and Scaffolding: An Architecture for a Theory of Cultural Change." In Developing Scaffolds in Evolution, Culture, and Cognition, edited by Linnda R. Caporael, James R. Griesemer, and William C. Wimsatt, 77-105. doi:10.7551/mitpress/ 9780262019552.003.0004.

Wylie, Alison. 1985. "The Reaction Against Analogy." Advances in Archaeological Method and Theory 8:63-111.

Wylie, Alison. 1999. "Rethinking Unity as a 'Working Hypothesis' for Philosophy of Science: How Archaeologists Exploit the Disunities of Science.” Perspectives on Science 7 (3): 293-317. doi:10. 1162/posc.1999.7.3.293.

Wylie, Alison. 2002. Thinking From Things: Essays in the Philosophy of Archaeology. Univ. of California Press.

Wylie, Alison. 2011. “Critical Distance: Stabilising Evidential Claims in Archaeology." doi:10.5871/ bacad/9780197264843.003.0014.

(c) 2019 Author(s)

This is an open-access article distributed under the terms of the Creative Commons Attribution 4.0 International license, which permits anyone to download, copy, distribute, display, or adapt the text without asking for permission, provided that the creator(s) are given full credit.

ISSN 2475-3025 